\title{
SOME OBSERVATIONS ON LAW AND INTERDISCIPLINARY RESEARCH*
}

\author{
ROBERT KRAMER†
} W HAVE ALL heard about the great virtues of interdisciplinary
research. Actually, this type of thing, often called law and the social sciences, has been going on now in academic and other circles for twenty or thirty years, or perhaps even a longer period of time. I, myself, have participated in a good bit of this interdisciplinary research, and I must say that I have a great deal of skepticism about the whole thing. The proposition is that if one can get a group of people together-experts or men trained in the different disciplines-and put them around a table for two or three days, and even have them agree on doing some research together, then, out of this productive work will come. This does not seem to me to work. Even if a school goes further, as some schools such as Yale have done, and expands its law faculty by putting on two or three economists, and two or three psychiatrists, and a couple of sociologists, I remain doubtful. My own experience is that the economists and sociologists and psychiatrists each form their own little club within the faculty. They dutifully attend the law faculty meetings, and they dutifully speak up whenever they are called upon; but they keep right within their own tight little disciplines. And the lawyers similarly keep right within their own tight discipline. They each learn a little bit about the jargon of the other, so that they can talk nicely at conferences or cocktail parties, but not very much more is accomplished.

As a matter of fact, if one reviews the literature on the subject, he will find that scarcely a year passes in which a learned journal of sociology or law, or whatever field he picks, fails to carry a brave article with a manifesto that what we need is interdisciplinary research. The article goes on to say what a wonderful thing this would be, and how productive it will be, and outlines a splendid program that can be accom-

* Based on a paper read at the Pilot Conference, Institute of Family Law, Duke University, Durham, N. C., April 10, 1959.

$\dagger$ A.B. 1935, LL.B. 1938, Harvard University. Member of the District of Columbia and New York bars; Professor of Law, Duke University. Co-author [with C. L. B. Lowndes], Federal Estate and Gift Taxation (1956). Contributor to legal publications. 
plished with only three or four million dollars. The air is full of such articles, but if one digs a little deeper and tries to find any published results of actual interdisciplinary research, he is suddenly in a vacuum. One can almost count on the fingers of $a$ hand the number of studies that are actually the product of this interdisciplinary research that everyone is talking about.

I am curious as to why there has been so much talk, with everybody agreeing that this is marvelous, but with so very few people ever getting down and doing this work, actually digging into it. Professor Cohen is one of the few I know who has actually done such work, with two or three other people, and published the results. ${ }^{1}$ But it is really astonishing, despite all this talk that has been going on, at least since Huntington Cairns published his book on law and the social sciences, ${ }^{2}$ how little, to my knowledge, has been accomplished. As a matter of fact, I suspect that if one were to revise Huntington Cairns's book today and bring it up to date, there would be very little to add to most of his chapters with respect to interdisciplinary research. One would still have to do just about what he did-namely, pick out each of the individual disciplinessociology, law, and medicine-and indicate what has been done in each.

I may be wrong, but it strikes me that one of the difficulties is that one does not get such interdisciplinary research, or whatever one wants to call it, simply by getting men in the various disciplines together or even forming them into teams to do it. Probably what one must have is one man who combines within himself a thorough working knowledge and training in several of the disciplines. Of course, one can say that if it takes seven or more years for a man to become a lawyer, and eight or more years for him to become a doctor, and three or four more years for him to become a sociologist, how in the world in one lifetime can any one individual acquire this knowledge. Part of the answer is that I do not necessarily mean that a man has to get a formal degree in each one of the disciplines. There is such a thing, as self-education, and there is no reason why lawyers should not, through their own reading programs and study, succeed in mastering fellow disciplines. As a matter of fact, the average lawyer does a great deal of that. There are very few lawyers who try lawsuits who do not, at some time or another, have to master a good bit of the knowledge that psychiatrists have, that doctors have, that medical. specialists have, even that sociologists have.

\footnotetext{
${ }^{1}$ Cohen, Robson, \& Bates, Parental Authority: The Community and the LAW (1958).

Cairns, Law and the Social Sciences (1935).
} 
Many an eminent specialist, when he has been called as an expert witness and has been subject to cross-examination, has perhaps been amazed at the knowledge that the trial lawyer has shown in cross-examining. So, I think this is perfectly possible, but one cannot get it just by mixing the different people together. One must mix the disciplines together in one human brain, so to speak.

Then, there is another thing that interferes quite a bit-that is what simply might be called the jargon or the esoteric vocabulary that each discipline pretends to have. Of course, every science and every discipline must have its own specialized words and vocabulary. I plead guilty to the fact that the law has more than its share, but there is this to be said about law words that have special meanings. In the first place, a good many law words that originally had special meanings, just because the law is such an old discipline, have more or less now gone into common speech-words such as "right," "duty," "privilege," "crime," and "penalty." It is quite true that the layman may have erroneous or false ideas about what those words really mean, but the average layman can read an article using those words, and get a fair idea of what the lawyer is talking about. Secondly, when lawyers do use highly specialized words, such as "rule against perpetuities," "shifting uses," "springing uses," or "fee tails," most lawyers can give a fairly exact definition of what is meant by those words without too much difficulty, and it is not very much of an exaggeration to say that one could get most lawyers to agree on what is meant by those words.

Although it may simply reflect my ignorance, my impression is that when you get to some of the other social sciences, some of the newer ones particularly, the picture differs. In sciences like psychiatry and sociology, many of the words are so newly minted that they have not yet been worked into common speech. It also is very difficult to get an exact definition of many of these specialized words; and it may be even more difficult to get a group of psychiatrists or sociologists to agree on exactly what is meant. I have recently been reading several articles, which set forth about eighteen or twenty definitions of "neurosis" and "psychopathic" given by various eminent authorities and which point out that (a) the authorities disagree in their definitions, and (b) many of the definitions do not make very much sense anyway, since they convey little meaning. I am aware of the fact that it would be unfortunate if we had a monolithic discipline in which every psychiatrist agreed with every other psychiatrist. I am also aware of the fact that much research is not going to give certainty, because the most we can hope for is 
probability. Even granting that, however, it does seem that some of the disputes and battles of so-called expert witnesses in court have had rather unfortunate results.

Another troublesome problem is certainly as characteristic of lawyers as of members of other specialized disciplines. Men tend to be blinded to values of society which lie outside of their particular discipline and training. Thus, if one is interested primarily in doing something about the problem of illegitimate children because of the drain on public funds the support of such children entails, it seems simple to say: Sterilize all the women who ever have such children. If one looks at the problem within that very narrow context, this makes good sense. If one broadens his approach, however, and thinks about the other social and human values involved, such as civil liberties and personal rights, he may come to a different conclusion. This comes out forcefully, too, in some of the problems of the juvenile court. The juvenile court has done fine work, but many people are troubled by the way at least some juvenile courts have tended, in their preoccupation with rehabilitating the child or reforming the family, to overlook the fact that sometimes people do not want to be reformed, and that sometimes people do not want to be told what to do, even if the advice is wise.

A related problem is that sometimes in our specialized disciplines we tend to overlook public opinion. We put forward theories, solutions, and research which either are too far ahead of the community, its values, and beliefs, or fail to take into account the community's values and beliefs. It is here that work such as that of Professor Cohen in trying to ascertain the moral judgment of the community on various problems, ${ }^{3}$ may have great value and indicate what can be done. Somewhat along the same lines, anyone who works a long time in a specialized discipline has a tendency (and this is certainly true of lawyers) to overvalue that particular discipline, to have the feeling that the solution for all the world's problems will come through that discipline. When I read some of the rather extravagant claims of some psychiatrists that every criminal is simply a sick individual who, given sufficient psychiatric treatment, would be made a sane-that is, a well man-I wonder. Or, when I read the claims of some sociologists that every criminal is simply a product of his environment, and if you change his environment you will have an honest law-abiding citizen, I am skeptical. I do not doubt that there is some truth here, but I wonder if the whole truth is contained within that one discipline.

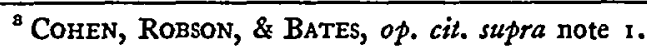


That brings me to another problem which I have already touched on. Any sort of science, whether it is a physical science or a social science (or even law, for that matter, to the extent that law is a science), has to face up to the fact that the most fundamental assumptions which it takes for granted today, and upon which it now builds its whole superstructure of theory and practice, tomorrow may be completely disproved. We are used to that in the field of the physical sciences. We know that the Euclidean geometry has been supplemented by the non-Euclidean geometry, and that the values of Newton have been modified by Einstein's, and that perhaps Einstein's in a few years are going to be modified by another theory. We have come to accept this; but in many of the social sciences, perhaps we have not quite adjusted to all the implications of this fact. Back in the 'twenties, there was a vogue for the theory that many of the evils of society, particularly crime, could be traced to feeble-mindedness. By and large, the trouble. with most criminals was simply that they were feeble-minded. There were the famous studies made of specific families, which purported to show that one feeble-minded parent back in 1790 had produced several. thousand criminals and delinquents of various types. As a result, a good many states decided to put the theory into practice, and passed laws providing for sterilization of feeble-minded people. The United States Supreme Court upheld these laws. ${ }^{4}$ The difficulty is, that a short: time after these states had enacted such laws, this theory was challenged, and challenged quite successfully. New studies showed that most of the criminals in our penitentiaries and prisons were by no means feebleminded. They were as intelligent as those outside prisons. The whole theory that crime was related to feeble-mindedness was discredited, at: least to the satisfaction of many people, although there are some who feel there is still something to it. The theory is gone, but the results of it are left on our statute books. The legislatures never get around to repealing these statutes, since very few people seem to be interested in them, and they linger on, as relics.

Or to take another example, even more controversial: In the opinion of the Supreme Court on segregation and public education, there is the famous footnote referring to writings of various sociologists and psychologists purporting to say that racial distinctions are invidious because they have harmful effects on the personality of children and people. ${ }^{5}$ Unfortunately, there are some authorities who would chal-

\footnotetext{
'Buck v. Bell, 274 U.S. 200 (1927).

${ }^{5}$ Brown v. Board of Education, 347 U.S. 483,494 \& n. II (1954).
} 
lenge this today; and, who knows, tomorrow the minority viewpoint may become the majority viewpoint. If that is true, should the Supreme Court reverse itself again? That raises problems which lawyers and legislatures must face: Can we afford, can we undertake every generation (or even sooner in the stepped-up pace of development) to rewrite our statutes and our legislation when the sociological, or psy. chiatric, or medical theory changes? Experience so far has indicated that our legislators are not apt to move that quickly.

There are other problems that cause difficulty. One that I shall touch on lightly, without trying to offend anyone, is that so many of these projects run into the difficulty of what I call "vested rights." What this means is that if most of us have spent twenty or thirty or forty years of our lives in a discipline, advocating and building up certain theories, and trying to prove their validity, we do not take it kindly if some young pup just out of college, hardly dry behind the ears, comes along and says: "Everything that you have been saying for twenty years is just plumb cockeyed; I can prove it." And he proceeds to prove it!

A psychiatrist has a "vested right," so to speak, in the theory that defects of personality are responsible for a good many of the ills of the world. A sociologist feels that defects of the environment are the key factor. And a clergyman feels that the problem is one of free will. Then there are those who come along and say, "What you really need is an over-all theory that will include all viewpoints; multicausation will do it." So they adopt a field theory which includes everything. This does little more than describe things; it does not attempt to explain, weigh, or evaluate them.

Often this results in something like the following: Somebody says, "Let us make a study and determine whether probation is any good as a method of penology. If you really used probation to the nth degree, and used it as wisely as possible, would it not have a widely beneficial effect?" They get three or four million dollars from a foundation, and they spend ten or twenty years doing it. They pick various pilot groups of prisoners. One group is given the finest probation treatment; and the other pilot group is given the very worst treatment, in the most out-moded dungeons of some state penitentiary. The researchers conclude that probation did not matter a "hoot"; that there were just as many men rehabilitated who spent their time in the dungeons as there were men rehabilitated who went on parole. If one is a parole officer, he is unsettled. He looks around and says, "How can 
I explain this study?" There are various ways. He can say, "You can't talk in terms of statistics. If we saved the soul or the life or the family of only one man, probation is worthwhile. You can't judge by averages." Or he can say, "After all, probation can't do everything. You've got to have other things. We certainly did a great deal even though it isn't shown." Or he can say, "Your criteria for success were wrong; after all, probation did make these people better adjusted. It did not prevent them from committing more crimes; but that is not the right test. They are better adjusted people in society; they are better criminals. That is their occupation. They know how to live better." Or he can say, "This was not really a fair test. You purported to give them the best kind of probation, but actually, the thing was sabotaged from the start. The legislature cut the funds for the program in half the second year, and the man in charge didn't really believe in it. You could not pay enough to get good people, so you had to hire hacks to do most of the work." Or he can say, "Your control groups are too small. If you had taken larger control groups, the results would have been quite different." Or he can say, "It is not fair because the men you used for probation were the very worst criminals; whereas, the men you uséd for your dungeon cases were the very best." He can go on. He can say, "There are other factors involved. There was a great depression during this time," or "We had a world war," or "We had a postwar boom," or "post-war bust." He is always safe in ending up by saying, "This thing needs further study. We need three or four million dollars more from another foundation to continue our work. What is really called for is more research and more study."

I hope that any future programs will not be expensive. There is the theory that if one just puts enough money into anything, one can succeed. We put millions of dollars into polio, and we got a preventive for it. If we put enough money on cancer research, we are bound to find a cure. If we put enough money into research on crime, penology, or juvenile delinquency, we are bound to solve it. I dissent from that point of view. We must remember the fact that if we put all of our money on one thing, it inay well mean that we are seriously neglecting other problems, not only because we do not have enough money for the other problems, but also because we will attract all the best brains and talent to our particular question and leave nothing at all for the other diseases or other problems of society.

- Cf. Cressy, The Nature and Effectiveness of Correctional Techniques, 23 LAW \& CONTEMP. ProB. 754, 76I-63 (1958). 
I should like to suggest, that actually a good bit of research can be done with relatively very little money. Another thing I should like to suggest is that there is no sense basing a research program on the theory that every man in the program is going to work twenty-four hours a day, seven days a week, 365 days a year. Yet, I am sure we have all seen research programs which more or less went on that basis so that the only way that the men who were in charge of it could accomplish what was set out was to work themselves to death. Similarly, it seems folly to set up a research program which calls for the services of a vast number of superhuman experts, because the truth is that one is very lucky, actually, in most research programs to get one or at the most two or three really first-class people to work. At least, that has been my experience. I look with, again, a somewhat skeptical eye on research programs which call for large teams of workers, because if the teams are to be composed of experts, one does not get that many experts at the prices you are willing to pay. Furthermore, a good many of our experts are perhaps prima donnas; they do not always work together so well in teams-the more expert they are, the less. inclined they may be to be a happy team. If one wants a happy team, he may have to settle for mediocrity. I am not at all sure but what most of the best research is done either by single individuals or by one or two people at the very most.

Another caution: In doing any sort of research one should be very skeptical about the initial data from which he starts. I have seen too many projects that take for granted figures that are furnished, sometimes by public officials, prison officers, or public bureaus, sometimes by private corporations or private persons, and draw all their conclusions and base their studies on those figures. Yet, all one needs to do is go back and dig a bit, and he discovers that the figures really are not worth much. The whole project can be blown sky high simply by attacking the unquestioned figures on which the study is based.

A final caution: One cannot expect to come out with certainty; the most one can hope for is probability. It is unfortunate that the public, viewing things from the standpoint of physical science and medicine, expects that one can always come up in his research project with a definite cure-with the conclusion that, for example, if one just will do the following five things, juvenile delinquency will vanish; if one just will do the following six things, there will be no more crime. 